\title{
Pesquisa na educação superior militar: uma perspectiva pedagógica
}

\section{Research in military higher education: a pedagogical perspective}

Rev. Bra. Est. Def. v. 3, nº 2, jul./dez. 2016, p. 73-90

\section{DÉBORA DURAN}

\section{INTRODUÇÃO}

A problemática que envolve a pesquisa na Educação Superior Militar, focalizada a partir das próprias práticas educativas que se constituem na dinâmica institucional, é bem mais complexa do que pode parecer à primeira vista.

Sem minimizar as pesquisas de caráter histórico, sociológico e antropológico realizadas de fora para dentro, interessa-nos, neste trabalho, realizar uma investigação de dentro para fora, com base na premissa segundo a qual a Pedagogia é a ciência da Educação, ou seja, a ciência que parte da prática educativa e a ela se dirige. Ao assumirmos tal definição, colocamo-nos diante do desafio de compreender, como professora civil, o objeto de estudo partindo da própria prática para, então, buscarmos nas outras ciências as referências necessárias à construção de um edifício teórico compatível com a complexidade do problema.

Apesar de não representar uma abordagem convencional a respeito do processo de formação profissional do oficialato, entendemos que nosso trabalho pode contribuir para a reflexão crítica sobre as relações entre civis e militares. Diante das contradições que podem impelir sínteses capazes de superar radicalizações, assumimos uma postura propositiva (dialogar sobre educação, com militares, a partir das práticas educativas) em vez de uma abordagem impositiva (argumentar sobre teorias da educação para militares).

Débora Duran - Doutora em Educação (USP), professora do Centro de Estudos de Pessoal e Forte Duque de Caxias (CEP-FDC) e Assessora Pedagógica do Centro de Educação a Distância do Exército (CEADEx). E-mail: debora-duran@uol.com.br. 
Existem inúmeras pesquisas sobre a influência dos governos militares nas transformações da política educacional brasileira, mas há pouco interesse pela investigação sobre as transformações ocorridas na educação dos militares desde o processo de Abertura. Tencionamos discutir os ranços e avanços, ou processos em curso que revelam perspectivas de abertura, destacando-se o diálogo, a cooperação e a parceria com instituições civis de ensino e pesquisa.

A Educação Superior Militar ${ }^{1}$ não é um tema recorrente nas investigações realizadas por pesquisadores civis. Como hipóteses possíveis - e prováveis - poderíamos elencar a falta de interesse pelo assunto e a dificuldade de se ter acesso aos estabelecimentos de ensino, aos documentos e, em última instância, à participação efetiva no cotidiano da caserna. Se, entre os pesquisadores civis, as investigações na área não são frequentes, entre os militares o tema também não se constitui num objeto privilegiado de pesquisa. Nesse caso, poderíamos inferir que a pesquisa e, mais especificamente, a pesquisa educacional, nas Forças Armadas, ainda precisa ser mais valorizada e que, em última instância, a Educação Superior Militar seria pouco problematizada.

Mesmo diante das referidas limitações, a instituição militar tem recebido, nas últimas décadas, um olhar mais atento por parte dos pesquisadores em geral. A ampliação dos grupos de pesquisa que se dedicam aos Estudos de Defesa, nas universidades, bem como a gradativa abertura das Forças Armadas no que diz respeito às parcerias acadêmicas, têm propiciado a ampliação do diálogo entre civis e militares. De acordo com Marques e Fucille (2015), os Estudos de Defesa no Brasil estão se fortalecendo como consequência de uma série de fatores. A consolidação de uma pequena comunidade epistêmica, ao longo da década de 1990, com a participação de representantes de diversas universidades brasileiras aliada a um conjunto de iniciativas governamentais, contribuiu para que os temas relativos à defesa nacional passassem a ter mais visibilidade no cenário nacional.

Ainda segundo os referidos autores, merecem destaque a estruturação do Ministério da Defesa, a Política de Defesa Nacional (PDN); a Estratégia de Defesa Nacional (END); o Livro Branco de Defesa Nacional (LBDN); o surgimento dos primeiros Programas de Pós-Graduação com área de concentração em Defesa, a partir de 2000, e a primeira graduação em Defesa na UFRJ, em 2010.

No mesmo sentido, dignas de nota são as propostas de Programas de Pós-Graduação stricto sensu das Escolas Militares de Comando e Estado-Maior das três Forças submetidas à avaliação do Ministério da Educação. No ano de 2012, a Escola de Comando e Estado-Maior do Exército obteve a autorização da Coordenação de Aperfeiçoamento de 
Pessoal de Nível Superior (CAPES) para o funcionamento do mestrado acadêmico e, a Universidade da Força Aérea (UNIFA), para o mestrado profissional em Ciências Aeroespaciais. No ano seguinte, o mestrado profissional em Estudos Marítimos, oferecido pela Escola de Guerra Naval (EGN), passou a ser recomendado. Desde 2016, todos os cursos de pós-graduação stricto sensu da ECEME são reconhecidos pelo MEC (mestrado, doutorado e pós-doutorado).

Apesar dos esforços conjugados e de uma produção acadêmica crescente, dificilmente encontramos trabalhos que problematizam a Educação Superior Militar sob a ótica pedagógica propriamente dita. Sendo assim, apesar de reconhecermos a importância das contribuições das denominadas ciências da educação, interessa-nos, no teor deste trabalho, discutir a questão da pesquisa na Educação Superior Militar com base na pedagogia, entendida como ciência da educação. Trata-se, pois, de tomá-la não apenas como campo de aplicação teórico-metodológica, mas como prática social constituída em contextos específicos que envolvem valores, fins e políticas.

\section{PEDAGOGIA: DAS CIÊNCIAS NA EDUCAÇÃO À CIÊNCIA DA EDUCAÇÃO}

\section{A realidade responde na língua em que é perguntada.}

(Santos 2003)

Afinal, qual seria a especificidade de uma pesquisa sobre Educação Superior Militar fundamentada na pedagogia? A priori, não há dúvida sobre a relação intrínseca entre educação e pedagogia, mas geralmente há inúmeras imprecisões sobre o que vem a ser pedagogia, isto é, se diz respeito a uma arte, ciência ou arte da ciência educativa. ${ }^{2}$ Uma das ideias mais difundidas é aquela segundo a qual a pedagogia seria uma área que se nutre das contribuições das denominadas ciências da educação, isto é, de conhecimentos produzidos por diversas ciências que tomam os fenômenos educativos como objetos de estudo e que podem contribuir para o seu desvelamento e compreensão. Esta é, sem dúvida, uma visão corrente, mas não é a única possível. Salvo melhor juízo, tais ciências tendem a ver a educação como uma área de aplicação teórico-metodológica, de fora para dentro, mas não propriamente como seu objeto de estudo específico, de dentro para fora.

Apesar de reconhecermos o valor das ciências da educação, com base nos estudos de Franco (2008), Libâneo (2002), Pimenta (2001) e Ferreira (2014), assumimos que a pedagogia é, por excelência, a ciência da educação, uma vez que parte da prática educativa e a ela se dirige.

A discussão epistemológica dos anos recentes está gestando um novo entendimento da pedagogia e das ciências da educação, frente 
às necessidades da prática. Assim, se tem afirmado que a pedagogia, ciência da educação, diferentemente das ciências da educação, toma a prática social da educação como ponto de partida e de chegada de suas investigações.

A pedagogia, enquanto ciência da prática da educação, é, ao mesmo tempo, constituída pelo fenômeno que estuda e o constitui, o que aponta para uma inversão epistemológica, pois até então a pedagogia tem sido considerada um campo aplicado de discursos alheios à educação enquanto prática social. A ressignificação epistemológica da pedagogia se dá à medida em que se toma a prática dos educadores como referência e para a qual significa. $\mathrm{O}$ objeto da pedagogia é a educação enquanto prática social. Daí seu caráter específico que a diferencia das demais: o de uma ciência da prática que parte da prática e a ela se dirige (Pimenta apud Franco 2008, 14).

Com base na pedagogia, anunciamos uma proposta de estudo ${ }^{3}$ que não exclui e nem tampouco minimiza as pesquisas fecundas que são desenvolvidas no âmbito de outras ciências. Destacamos, apenas, que o foco pedagógico, apesar de suas limitações, permite revelar algumas facetas importantes da Educação Superior Militar pelos olhos de quem atua, diariamente, nos contornos das Forças Armadas. No cotidiano dos estabelecimentos de ensino do Exército Brasileiro, os fenômenos educativos resistem a quaisquer tentativas simplificadoras de análise e interpretação, já que geralmente são mais complexos do que se supõe.

A rigor, temos o desafio de compreender a problemática da pesquisa na Educação Superior Militar tomando a prática cotidiana como ponto de partida e de chegada. Isso significa, em última instância, problematizar as ações educativas que são desenvolvidas na dinâmica institucional e que envolvem, por sua vez, diversas tensões e contradições. Assumir a prática educativa como ponto de partida para a investigação não significa aderir ao pragmatismo, já que o que se pretende é justamente evitar a redução do educacional ao instrucional, pois os problemas pedagógicos não podem ser reduzidos à didática ou à metodologia de ensino - ainda que possam envolvê-las. Tomar a prática educativa como ponto de chegada significa destacar a importância da pedagogia para além da identificação de problemas, enquanto referencial potencialmente capaz de promover a articulação entre práticas e teorias com vistas à elaboração de possíveis soluções comprometidas com a transformação dos processos educativos.

A prática, nesse sentido, não se reduz e nem tampouco se limita aos fazeres das aulas ou das instruções, uma vez que está intimamente relacionada aos valores, aos fins e às próprias políticas educacionais do Exército. 
Em outras palavras, o compromisso pedagógico não pode se render a uma concepção instrumentalizadora (como dar boas aulas ou aperfeiçoar as técnicas de ensino). Mesmo que sua legitimidade não seja devidamente reconhecida, a pedagogia tende a desempenhar um papel crucial no processo de organização e orientação das atividades realizadas no âmbito da instituição, de modo que pode interferir nas relações de poder, bem como nas relações interpessoais que permeiam os processos que envolvem a circulação de conhecimentos e a dinâmica dos cursos e das políticas educacionais em vigor (Ferreira 2014).

De acordo com Saviani (1986), as teorias que analisam a realidade educacional e suas relações com a sociedade sem ter como objetivo a formulação de diretrizes capazes de orientar a atividade educativa não podem ser consideradas como pedagógicas. Nesse sentido, entendemos que a pedagogia não é neutra, mas essencialmente política, pois seu compromisso com a educação intencional envolve a investigação dos diversos fatores que interferem na formação humana e, consequentemente, a proposição - que não significa imposição - de possíveis perspectivas ou vias de transformação.

A problematização de caráter pedagógico, a rigor, está alinhada com a perspectiva da totalidade. Destarte, toda e qualquer investigação de caráter educacional, ainda que seja delimitada, não pode ser satisfatoriamente desenvolvida com base numa abordagem parcial ou reducionista. No caso específico da Educação Superior Militar, é mister destacar que a pedagogia não deve ser reduzida a uma tecnologia, isto é, a uma área responsável pelo estudo da planificação, das técnicas e dos meios necessários à efetividade dos processos de ensino e aprendizagem. Antes, e sobretudo, essa ciência tenciona compreender, com base nas questões que emergem nas dinâmicas da prática educativa, complexos processos com especial atenção aos aspectos subjetivos, sociais e institucionais (Freire, Albuquerque e Magalhães 2010).

Com base nos argumentos apresentados, notamos que uma pesquisa de cariz pedagógico não é tarefa das mais fáceis. Em primeiro lugar, a investigação sobre a Educação Superior Militar, com base nas práticas, exige a atuação do pesquisador como profissional possuidor de vínculos com a instituição e que seja conhecedor da ciência pedagógica, ou seja, trata-se de uma condição peculiar. Ademais, no plano interno, existem diversos desafios, dentre os quais podemos destacar os que se seguem.

A pesquisa e, como consequência, a problematização, nem sempre é valorizada como condição necessária à compreensão da realidade e ao necessário processo de transformação institucional. A pedagogia, em sentido pleno, não é por todos compreendida, de modo que a prevalência da perspectiva instrumental tende a fragilizar a articulação entre os aspectos his- 
tóricos, sociológicos, antropológicos e psicológicos no estudo das questões educacionais. Como já destacamos em trabalhos anteriores, a identificação de um determinado problema não é sinônimo de indisciplina, mas de compromisso profissional e competência intelectual. A esse respeito, mais uma vez, valemo-nos das palavras do Coronel Serrano, ex-subcomandante da ECEME: "é preciso despir a ideia de crítica de uma eventual conotação negativa, pois acredito que uma instituição que não se critique seja uma instituição imóvel, e a imobilidade é degeneradora" (Serrano 2004, p. 46).

Há ainda um fator adicional que diz respeito à incursão de militares e civis que atuam na área em grupos de pesquisa civis, uma vez que dificilmente os problemas da Educação Superior Militar são reconhecidos como relevantes na pauta das discussões acadêmicas. Desse modo, são limitadas as chances para a discussão da referida temática em espaços propícios à elaboração do conhecimento científico e ao consequente diálogo enriquecedor.

\section{PESQUISA COMO PRINCÍPIO CIENTÍFICO E EDUCATIVO NA EDUCAÇÃO SUPERIOR MILITAR}

Feitos os devidos esclarecimentos, pretendemos apresentar algumas considerações sobre as possíveis contribuições de uma perspectiva pedagógica para a investigação sobre a pesquisa na Educação Superior Militar. ${ }^{4}$ Partindo das práticas que se constituem e se revelam nos estabelecimentos de ensino, podemos então compreender melhor os problemas relacionados à pesquisa, bem como apontar para algumas vias de superação.

Em consonância com os argumentos de Saviani (1996), entendemos por problema pedagógico uma questão ou conjunto de questões relacionadas à educação que reclamam por respostas, algo que não se conhece ou que não se compreende e que se faz necessário saber devido à sua importância. O problema de pesquisa, portanto, impõe a busca de respostas - impõe-se.

Diante do exposto, seria então razoável perguntar: Por que a pesquisa, no âmbito da Educação Superior Militar, se constitui num problema de pesquisa?

Em primeiro lugar, precisamos esclarecer os motivos pelos quais a ideia de pesquisa passou a assumir um lugar de destaque na educação contemporânea e, mais especificamente, na Educação Superior Militar. Quando falamos em pesquisa na Educação Superior, geralmente nos vêm à mente as ideias relacionadas à produção do conhecimento científico, ao desenvolvimento, ao posicionamento crítico diante da realidade e até mesmo às exigências relacionadas à titulação. De fato, tais aspectos não podem ser desconsiderados quando o assunto é pesquisa. No entanto, como já destacamos em trabalho anterior (Duran 2010), atualmente as configurações 
do mundo globalizado apresentam novas exigências à educação, em suas múltiplas dimensões.

Machado (1997) afirma que as relações entre o mundo do conhecimento e o mundo do trabalho têm sofrido intensas transformações. $\mathrm{Na}$ Antiguidade, a palavra mais adequada para fazer referência a esses dois mundos seria separação, ao passo que na época da Revolução Industrial, séculos mais tarde, o mais correto seria falar em aproximação, dada a crescente necessidade de aplicação do conhecimento ao trabalho.

A partir da Segunda Guerra Mundial, com o ritmo acelerado do avanço tecnológico e, posteriormente, com o aprofundamento do processo de globalização, a informação transformou-se no principal fator de produção do sistema capitalista, fenômeno que tem anunciado a quase fusão entre os mundos do conhecimento e do trabalho. Atualmente, a pesquisa é condição sine qua non à subsistência da sociedade global (Ianni 2000) ou sociedade em rede (Castells 1999), uma vez que o conhecimento científico é aplicado à geração de novos conhecimentos com o apoio das tecnologias digitais de informação e comunicação (TDIC) que emergem em tempos de Revolução Informacional (Lojkine 1999).

Diante das transformações em curso, de acordo com Vesentini (2007), deparamo-nos com novas geopolíticas que relativizam a guerra militar, já que novos atores e sujeitos são levados em consideração. Visacro (2009), ao discutir as especificidades da Guerra de Quarta Geração (4GW - Fourth Generation Warfare), assevera que os desafios atuais impõem às Forças Armadas a formação de um novo tipo de profissional, uma vez que o modelo vigente garantiria, no máximo, uma profissionalização compatível com o perfil dos soldados de segunda geração. ${ }^{5}$ Não por acaso, a Política Nacional de Defesa (PND 2012) e a Estratégia Nacional de Defesa (END 2012) também destacam a importância de se forjar um novo tipo de combatente, isto é, um profissional flexível, versátil e ágil na tomada das decisões. O discurso oficial é claro em relação ao que se espera dos militares no plano ideal, mas deixa às escuras os desafios a serem superados para a consecução das finalidades propostas.

Do ponto de vista pedagógico, entendemos que as novas exigências impostas à profissionalização dos militares apontam, necessariamente, para algumas questões candentes. Dentre elas, não sendo a principal, nem tampouco a menos importante, destaca-se a da pesquisa como princípio científico e educativo. Pensar a pesquisa nesses termos significa reconhecer sua legitimidade não apenas como produto final dos cursos, mas como prática educativa ao longo de todo o processo formativo. Nessa linha de raciocínio, a importância da pesquisa não pode ser reduzida à elaboração de monografias, dissertações e teses para a conferência de titulação. 
A rigor, não há dúvidas sobre a importância e a legitimidade da pesquisa voltada à produção do conhecimento científico, já que não é apenas desejável, mas necessária. Contudo, não se trata de fazer a defesa de uma Educação Superior Militar bacharelesca destinada à formação de cientistas profissionais, mas de romper com o modelo de ensino baseado no que poderíamos chamar de "pedagogia da resposta", um modelo pedagógico fundamentado nas ideias de previsão e controle que se desdobra em metodologias de caráter mecanicista.

Os desafios complexos da contemporaneidade impõem a superação do que se convencionou chamar de paradigma instrucional ou modelo reprodutivista de educação, tanto na educação de civis como de militares. Não se trata de mera coincidência o destaque dado às ideias de flexibilidade, cooperação, autonomia e resolução de problemas nos textos oficiais referentes à educação nacional e, especificamente, àquelas atinentes à defesa nacional. Se o novo cenário da denominada Sociedade da Informação aponta para a necessidade de formação de um novo tipo de profissional civil; no caso dos militares, a situação não é diferente. As finalidades educacionais podem até ser distintas, mas diversos princípios pedagógicos são comuns à formação dos dois grupos, respeitadas as devidas especificidades.

Diante do exposto, Demo (2000) faz um alerta explícito quanto à necessidade de superação da visão corrente, segundo a qual a pesquisa estaria restrita às lides científicas. Ela deve ser reconhecida, ao longo de todo o processo de educação formal, como atividade necessária à formação de sujeitos que sejam capazes de dialogar crítica e criativamente com a realidade circundante, bem como hábeis para compreender a natureza complexa dos problemas que a envolvem. Para o autor, a cultura da resposta imperante nas escolas e universidades geralmente concorre para a formação de imitadores e fazedores de provas.

No caso específico da Educação Superior Militar, a advertência também é válida. As políticas educacionais dos últimos vinte anos - Processo de Modernização do Ensino (PME) e Ensino por Competências - explicitam a importância do aprender a aprender, da autonomia e de novas metodologias. No entanto, a superação dos modelos pedagógicos tradicional e tecnicista ainda se constitui num desafio a ser superado. Diga-se de passagem, nem sempre a superação do modelo tradicional ocorre paripassu com a superação do modelo tecnicista, já que não raro se confunde educação de qualidade com quantidade de técnicas de ensino, para além das aulas expositivas.

Diante do exposto, entendemos que a prática da pesquisa, se for devidamente reconhecida como princípio educativo ao longo do processo formativo, também irá se desdobrar em trabalhos científicos de qualidade, como consequência. Portanto, as expectativas de trabalhos inovadores na 
pós-graduação lato e stricto sensu não poderão ser plenamente atendidas se não houver um trabalho intensivo e sistematizado durante a graduação.

\section{PESQUISA COMO DESAFIO PEDAGÓGICO}

As peculiaridades da Educação Superior Militar apontam para a pesquisa como um grande desafio pedagógico. Nesse sentido, a compreensão da problemática que a envolve nas práticas dos estabelecimentos de ensino reclama por uma reflexão de caráter interdisciplinar fundamentada nos estudos históricos, sociológicos, antropológicos e psicológicos.

A história da Educação Militar é marcada por diversos dilemas e desafios. Dentre os dilemas, talvez um dos principais esteja relacionado à falta de precisão sobre a finalidade da formação dos oficiais. Motta (1998) e Carvalho (2005) destacam o impasse histórico entre a defesa do perfil dos tarimbeiros, voltados ao combate, à prática; e dos bacharéis, voltados à intelectualidade e à atuação política. Em certo sentido, esse dilema permanece até os dias atuais, sendo que a prática da pesquisa é comumente atrelada ao bacharelismo. Mesmo diante das transformações do mundo contemporâneo e do que poderíamos chamar de novas guerras, no senso comum da caserna a ideia de pesquisa está descolada e deslocada da prática, por ser considerada como atividade intelectual e meramente teórica. Não há, entre os militares, um consenso geral sobre a importância da pesquisa na educação formal (inicial e continuada) e nem tampouco em relação às suas atividades laborais.

Um detalhe que merece especial destaque diz respeito ao Estatuto de 1810, documento de criação da Real Academia Militar. Em seu teor, o Conde de Linhares registrou diversas orientações de caráter didático, destacando-se a importância dos exercícios de recapitulação e a aplicação prática dos conhecimentos teóricos. Em relação à pesquisa, temos a gênese do que hoje denominamos de pesquisa como princípio educativo.

Mas, nesses preciosos sábados não se visava apenas, à fixação da matéria aprendida. Neles, o professor procuraria desenvolver no aluno o gosto da pesquisa ("preparando-lhes o espírito para tentarem a descoberta") e a capacidade inventiva ("despertando o gênio inventor de que a natureza possa ter dotado alguns dos discípulos”). E, para tal fim, deveria colocar os alunos diante daquilo que hoje chamamos "tarefas de estudo" ("dará de certas em certas épocas problemas"), ajustados à capacidade de cada um ("análogos ao aproveitamento dos discípulos) (Motta 1998, 29).

Ao que tudo indica, os ideais pedagógicos que inspiraram o idealizador da academia eram compatíveis com o que posteriormente seria chamado de 
pedagogia ativa. No entanto, a análise histórica de Motta (1998) revela que tal concepção muitas vezes ficou restrita à letra fria da lei, já que a articulação entre teoria e prática, a pesquisa e outras iniciativas inovadoras nunca foram, de fato, implementadas em sua plenitude. Dos primórdios aos dias atuais, o modelo pedagógico tradicional ainda não foi completamente superado e a problemática metodológica reveste-se de grande complexidade.

No que diz respeito aos aspectos socioantropológicos, de acordo com Castro (2004, 34), "comparada a outras profissões, a militar representaria um caso-limite sociológico, contribuindo para uma grande coesão ou homogeneidade interna ("espírito de corpo"), mesmo que frequentemente e ao preço de um distanciamento entre os militares e o mundo civil”. Numa perspectiva pedagógica, essa afirmação leva-nos a refletir sobre a homogeneidade $^{6}$ como uma das características do Sistema de Educação e Cultura do Exército.

Uma parte significativa dos conteúdos curriculares dos cursos é definida e fundamentada na doutrina, manuais, diretrizes, normas, regulamentos e outros materiais de referência produzidos pela própria instituição. Como consequência de um processo de profissionalização peculiar, ocorre um gradativo distanciamento do mundo civil e, em certo sentido, o direcionamento do repertório profissional e cultural. As poucas oportunidades para o confronto entre diferentes perspectivas acabam por gerar uma certa dificuldade na compreensão de problemas e de suas possíveis soluções numa perspectiva complexa.

No que diz respeito à forma, a legislação deve ser rigorosamente cumprida por todos os estabelecimentos de ensino, respeitadas algumas peculiaridades. As normas relacionadas à elaboração de currículos, metodologia de ensino e avaliação são comuns à instituição como um todo e, a princípio, não há nenhum impeditivo formal em relação à pesquisa, em sentido geral. Ao contrário, por meio de uma análise minuciosa da legislação educacional dos últimos vinte anos, pudemos constatar que a ideia de pesquisa, em si, não é um problema, ainda que possa estar envolta em algumas contradições. Contudo, na dinâmica das práticas educativas encontramos diversos entraves para que o potencial da pesquisa seja devidamente explorado, principalmente em função do processo de avaliação que, não raro, está atrelado ao processo de classificação.

Quando o assunto é avaliação, a reflexão pedagógica aponta para a necessidade de uma análise dos aspectos relacionados à psicologia, especificamente das teorias da aprendizagem que norteiam as práticas educativas na Educação Superior Militar. Como ponto de partida, devemos esclarecer que a classificação dos alunos depende da nota final, e esta, por sua vez, impõe a ordem de escolha para as transferências ao término da graduação 
em Ciências Militares realizada na AMAN. Apesar dos esforços envidados pela instituição no intuito de valorizar o desempenho profissional ao longo da carreira, a classificação ainda impera em certos processos de transferência, promoção e escolha para missões no exterior. A aristocracia do grau ${ }^{7}$ revela-se, inclusive, no processo de socialização entre os próprios militares.

Nos demais cursos que envolvem classificação, a avaliação define a vida do militar e a de sua família e, por esse motivo, há grande preocupação com a objetividade dos instrumentos de avaliação. Diante desse quadro que exige uma mensuração precisa, geralmente a prova formal é eleita como instrumento de avaliação somativa ao término dos cursos cujas portarias de criação determinam a classificação. Não por acaso, as normas que orientam a elaboração das provas são muito rigorosas, devidamente alinhadas com o tecnicismo fundamentado no comportamentalismo de Skinner e na taxionomia da Bloom.

Na prática, o processo avaliativo deve estar ancorado em questões cujos enunciados exijam respostas para as quais seja possível atribuir "gaivotas" com a máxima precisão. Com foco na previsão e controle dos resultados, a correção minuciosa das respostas deve estar de acordo com o conteúdo dos gabaritos previamente elaborados pelos instrutores e professores.

Apesar de ser bem-intencionado e organizado, esse processo representa um nó górdio no que diz respeito às perspectivas de inovação pedagógica e à própria pesquisa enquanto princípio científico e educativo. Como as provas definem a vida profissional dos oficiais, é evidente que os esforços de estudo são direcionados com vistas ao melhor resultado possível num processo altamente competitivo. Sendo assim, importa estudar o conteúdo que cai na prova e, ademais, o modo pelo qual será cobrado. Se a prova geralmente é elaborada com base em padrões previsíveis, então o esforço máximo dos discentes se dá no sentido da reprodução, ou seja, a resposta deverá estar de acordo com o gabarito ou o mais próximo possível da solução-padrão. Por não valer nota e por não contribuir para a efetiva consecução do grau almejado, em termos de conteúdo e forma, a pesquisa passa a ser relegada a segundo plano.

Outro aspecto que merece especial atenção diz respeito ao descompasso entre as propostas inovadoras inerentes às políticas educacionais do último vintênio e a questão da avaliação. Nas práticas cotidianas, existe um dilema entre a metodologia das aulas e a metodologia das provas, já que nem sempre é possível garantir total coerência entre as situações dinâmicas e interativas promovidas em algumas aulas/instruções e o caráter ainda conservador da avaliação somativa. Apesar dessa limitação que permanece como um desafio a ser superado, no que diz respeito às avaliações diagnóstica e formativa, vale destacar que já podem ser identificados avanços considerá- 
veis, de modo que alguns instrutores e professores civis têm apresentado alternativas diversificadas para tal fim.

Em face do exposto, entendemos que existem diversas especificidades que são próprias da Educação Superior Militar. No entanto, existem pontos de convergência em relação aos desafios da Educação Superior em geral, destacando-se a falta de orientadores experientes, a sobrecarga de trabalho dos instrutores e docentes, a falta de tempo destinado à pesquisa, a dificuldade de problematização e a própria redação acadêmica, no caso dos alunos, o que inclui as dificuldades relacionadas à fundamentação teórico-metodológica e à normatização.

\section{CONCLUSÃO}

A pedagogia, apesar de não ser frequentemente assumida como base teórica no âmbito dos estudos sobre Defesa, revela-se como ciência capaz de contribuir de forma efetiva para a pesquisa sobre a Educação Superior Militar. Assumida como ciência da educação, a pedagogia reconhece a prática como seu ponto de partida e de chegada, de modo que a problematização de caráter pedagógico tem sua gênese na própria dinâmica da educação formal que se dá nos estabelecimentos de ensino. Não se trata, como vimos, de tomar a educação como campo de aplicação, mas de reconhecê-la como prática social constituída em contextos específicos que envolvem valores, fins e políticas. A pedagogia, portanto, não se reduz a uma tecnologia e nem é neutra.

Do ponto de vista pedagógico, o problema da pesquisa na Educação Superior Militar reveste-se de grande relevância social, uma vez que aponta para a necessidade de uma nova cultura de aprendizagem que seja capaz de superar os modelos tradicional e tecnicista de ensino. Em tempos de cibercultura, no contexto do mundo globalizado, o paradigma instrucional não é mais adequado e nem tampouco suficiente para a formação dos combatentes do século XXI. O perfil do militar exigido na contemporaneidade não mais se limita às ações responsivas, já que as novas configurações da guerra apontam para a necessidade de profissionais que sejam capazes de reconhecer a complexidade dos problemas e, consequentemente, de vislumbrar diversas vias de solução.

Reconhecer a legitimidade da pesquisa enquanto princípio científico e educativo é condição sine qua non à superação da "pedagogia da resposta", um desafio comum às instituições de ensino militares e civis. No caso específico do Exército Brasileiro, as políticas educacionais das duas últimas décadas, denominadas Processo de Modernização do Ensino (PME) e Ensino por Competências, revelam-se como horizontes promissores no que diz res- 
peito a novas perspectivas metodológicas. Ainda que possamos, no plano legal, identificar diversos vetores de transformação, o cotidiano real nos revela que muitos desafios ainda precisam ser superados. Dentre eles, destacam-se o dilema da avaliação aliada ao processo de classificação, o ideário segundo o qual pesquisa é sinônimo de bacharelismo e a falta de condições efetivas para a realização de atividades afins. Por outro lado, no que diz respeito à produção do conhecimento científico, o reconhecimento dos cursos de pós-graduação stricto sensu da ECEME representa um verdadeiro marco na Educação Superior Militar. O diálogo com instituições civis de ensino e pesquisa e a produção acadêmica estão sendo ampliados gradativamente como consequência do trabalho colaborativo de docentes civis e militares.

Parafraseando Olson (1995), reconhecemos que a pesquisa não é o único problema, mas também não é a única solução. Ainda assim, importa destacar que a valorização da pesquisa na formação inicial e continuada do oficialato pressupõe a abertura, em suas múltiplas dimensões. Das repostas às perguntas, a prática da pesquisa pode contribuir para a ampliação dos conhecimentos e dos referenciais de estudo, para a compreensão dos conflitos contemporâneos na perspectiva da complexidade e, fundamentalmente, para o diálogo necessário entre civis e militares em prol da consolidação de uma cultura de Defesa.

Propomos, assim, um trocadilho que sintetiza a ideia de complementaridade na formação profissional militar: nem tarimbeiros, nem bacharéis: "tarimbéis"! Teoria e prática, habilidade operacional e performance intelectual devem ser consideradas como faces indissociáveis da Educação Superior Militar. Eis o desafio pedagógico relacionado à pesquisa como princípio científico e educativo.

\section{REFERÊNCIAS}

Cambi, F. 1999. História da Pedagogia. São Paulo: UNESP.

Castells, M. 1999. A Sociedade em Rede. São Paulo: Paz e Terra.

Castro, C. 2004. O espírito militar. Um antropólogo na caserna. Rio de Janeiro: Jorge Zahar.

Carvalho, J. M. de. 2005. Forças Armadas e Política no Brasil. Rio de Janeiro: Jorge Zahar.

Demo, P. 2000. Pesquisa-princípio científico e educativo. 7. ed. São Paulo: Cortez. 2002. Educar pela pesquisa. 5. ed. Campinas: Autores Associados. 
Duran, D. 2010. "Ciências Militares, Militares e Ciência: o desafio da pesquisa no Exército Brasileiro”. In: Gomes, J. C., Schaffel, S. L., Duran, D. Ciências Militares em Foco. Rio de Janeiro: Centro de Estudos de Pessoal (CEP).

Ferreira, L. S. 2014. "Pedagogia como ciência da educação: retomando uma discussão necessária”. Revista Brasileira de Estudos pedagógicos, 91 (227), 233-251.

Franco, M. A. S. 2008. Pedagogia como ciência da educação. 2. ed. São Paulo: Cortez.

Freire, F. F., Albuquerque, A. C., Magalhães, S. M. da C. 2010. "Uma concepção pedagógica de Ensino Militar: reflexões para a elaboração de um plano de desenvolvimento do ensino militar". In: Gomes, J. C., Schaffel, S. L. Currículo: limites e possibilidades. Rio de Janeiro: Centro de Estudos de Pessoal (CEP).

Gomes, J. C., Schaffel, S. L., Duran, D. 2010 Ciências Militares em Foco. Rio de Janeiro: Centro de Estudos de Pessoal (CEP).

Ianni, O. 2000. A sociedade global. 10. ed. Rio de Janeiro: Civilização Brasileira.

Libâneo, J. C. 2002. Pedagogia e pedagogos, para quê? 6. ed. São Paulo: Cortez.

Lojkine, J. 1999. A Revolução Informacional. São Paulo: Cortez.

Machado, N. J. 1997. Cidadania e Educação. São Paulo: Escrituras.

Magalhães, S. M. da C. 2015. O Processo de Modernização do Ensino no Exército Brasileiro. Rio de Janeiro: [s/n].

Marques, A., Fucille, A. 2015. "Ensino e Pesquisa em Defesa no Brasil: Estruturação do Campo e Desafios". Revista Brasileira de Estudos de Defesa, 2 (2), 53-69.

Motta, J. 1998. Formação do oficial do Exército Brasileiro: Currículos e regimes na Academia Militar - 1810-1944. Rio de Janeiro: Companhia Brasileira de Artes Gráficas.

Olson, D. R., Torrance, N. 1995. Cultura escrita e oralidade. São Paulo: Ática.

Pimenta, S. G. 2001. Pedagogia, Ciência da Educação? 3. ed. São Paulo: Cortez.

Santos, B. de S. 2003. Um discurso sobre as ciências. São Paulo: Cortez.

Saviani, D. 1986. Educação: do senso comum à consciência filosófica. 8. ed. São Paulo: Cortez.

Serrano, M. O. L. S. 2004. Cultivar talentos. PADECEME, 8, 44-47. 
Vesentini, J. W. 2007. Novas geopolíticas. São Paulo: Contexto.

Visacro, A. 2009. Guerra Irregular. Terrorismo, guerrilha e movimentos de resistência ao longo da história. São Paulo: Contexto. 


\section{NOTAS}

1. No Exército Brasileiro, os estabelecimentos de ensino são subordinados ao Departamento de Educação e Cultura (DECEx), que por sua vez é constituído por diversas diretorias. No caso específico da Diretoria de Educação Superior Militar (DESMil), os estabelecimentos de ensino a ela subordinados são os seguintes: Escola de Comando e Estado-Maior do Exército (ECEME); Escola de Aperfeiçoamento de Oficiais (EsAO); Escola de Saúde do Exército (EsSEx); Escola de Formação Complementar do Exército (EsFCEx); Academia das Agulhas Negras (AMAN); Escola Preparatória de Cadetes do Exército (EsPCEx) e Centros de Preparação de Oficiais da Reserva (CPOR) do Rio de Janeiro, São Paulo, Belo Horizonte, Porto Alegre e Recife. Vale destacar que existem outros estabelecimentos de ensino nos quais são realizadas atividades de pesquisa, apesar de serem subordinados a outras diretorias, como é o caso do Centro de Estudos de Pessoal e Forte Duque de Caxias (CEP-FDC) e do Instituto de Pesquisa de Capacitação Física do Exército (IPCFEx), dentre outros. Ademais, merece ainda destaque o Instituto Militar de Engenharia (IME) que não é subordinado a nenhuma diretoria do DECEx, mas ao Departamento de Ciência e Tecnologia (DCT).

2. Para um estudo mais aprofundado sobre esse dilema conceitual, ver Franco (2008) e Cambi (1999).

3. O teor deste trabalho apresenta algumas reflexões que norteiam a pesquisa em andamento no estágio pós-doutoral da Escola de Comando e Estado-Maior do Exército (ECEME): "Pesquisa na Educação Superior Militar: políticas e práticas”. Trata-se de uma investigação sobre as políticas educacionais dos últimos vinte anos e suas implicações na prática educativa, destacando-se a linha de ensino militar bélico.

4. De acordo com o Regulamento da Lei de Ensino do Exército, o ensino no Exército desenvolve-se em quatro Linhas de Ensino Militar: Bélico, destinada à qualificação continuada de pessoal necessário à direção, ao preparo e ao emprego da Força Terrestre; Científico-Tecnológico, destinada à qualificação continuada de pessoal necessário à direção e à execução das atividades científico-tecnológicas; de Saúde, destinada à qualificação continuada de pessoal necessário à direção e à execução das atividades de saúde; e Complementar, destinada à qualificação continuada de pessoal necessário ao desempenho de atividades não enquadradas nas linhas anteriores e definidas em legislação específica. As questões discutidas neste texto estão focadas na Linha de Ensino Militar Bélico, em sentido amplo, já que cada estabelecimento de ensino apresenta suas próprias peculiaridades, dinâmicas e modus operandi que não podem ser generalizados em sua totalidade. 
5. De acordo com o autor, a segunda geração diz respeito à "guerra do atrito", linear, com padrões formais de planejamento e métodos rígidos de execução. O propósito é "concentrar o máximo de poder relativo de combate e cerrar sobre o inimigo para destrui-lo".

6. O reconhecimento da homogeneidade não pode, contudo, ser tomado em sentido absoluto, mas relativo. A esse respeito, Magalhães (2015) sustenta que as instituições militares não são totalmente homogêneas, nem tampouco monolíticas e petrificadas.

7. Esse termo foi cunhado pelo aluno Major Marcos Gomes de Oliveira numa aula do Curso de Coordenação Pedagógica, no Centro de Estudos de Pessoal e Forte Duque de Caxias (CEP-FDC), e diz respeito à extrema valorização da classificação, do grau, principalmente em relação aos "zeros de turma" (do primeiro ao nono colocados na AMAN).

8. As gaivotas correspondem aos escores, ou seja, à pontuação alcançada na apresentação de respostas corretas. 
PESQUISA NA EDUCAÇÃO SUPERIOR MILITAR:

UMA PERSPECTIVA PEDAGÓGICA

\section{RESUMO}

As questões relacionadas à Educação Superior Militar podem ser investigadas com base em diferentes aportes teóricos. Como contribuição e como desafio propomos, nos contornos deste trabalho, um foco pedagógico para o estudo sobre a pesquisa como princípio científico e educativo na Educação Superior Militar.

Palavras-chave: Pesquisa; Educação Superior Militar; Pedagogia; Exército.

\section{ABSTRACT}

Issues related to Military Higher Education can be investigated based on different theoretical contributions. As a contribution and challenge, we propose, in the context of this work, a pedagogical focus for the study on the research as a scientific and educational principle in Military Higher Education.

Keywords: Search; Military Higher Education; Pedagogy; Army. 